\title{
LXX. Triple pendulums with mutual interaction and the analogous electrical circuits.-I
}

\section{Prof. E.H. Barton F.R.S. \& H.M. Browning M.Sc.}

To cite this article: Prof. E.H. Barton F.R.S. \& H.M. Browning M.Sc. (1920) LXX. Triple pendulums with mutual interaction and the analogous electrical circuits.—I, Philosophical Magazine Series 6, 40:239, 611-618, DOI: 10.1080/14786441108636166

To link to this article: http://dx.doi.org/10.1080/14786441108636166

曲 Published online: 08 Apr 2009.

Submit your article to this journal $\lceil\pi$

Џ Article views: 3

Q View related articles $\square$

Citing articles: 1 View citing articles ๘ 
10. Experiments on the disappearance of carbon monoxide in the glow discharge are described.

11. The results are discussed and explained by supposing that the glow causes a chemical change in the gas, which is reversible. The recognition of this reversibility seems necessary to explain the phenomena. The disappearance of other gases, illustrating other types of action, will be discussed in the sequel.

Research Laboratories of the General Electric Co., Ltd., April 16, 1920. Hamımersmith.

LXX. Triple Pendulums with Mutual Interaction and the Analogous: Electrical Circuits.-I. By Prof. E. H. BARton, F.R.S., and H. M. Browning, M.Sc.*

[Plates XI.-XIII.]

\section{Introduchion.}

$\mathbf{M}^{\mathrm{r}}$

ECHANICAL analogies to two circuits coupled together have been used to show the type of vibrations set up by the latter. (See "Coupled Vibrations," Phil. Mag. Oct. 1917, Jan. 1918 and July 1918.)

The mathematical theory of these circuits is comparatively simple, but the visual results of the mechanical analogy tend to elucidate and interpret the theory.

In the case of three cireuits or three pendulums which are arranged to act on one another, the theory is more complicated, although in certain cases it can be resolved into a somewhat simpler form.

The experiments were carried out with a modified form of: the apparatus shown in figs. 1 and 2 of "Vibrations under Variable Couplings" (Phil. Mag. Oct. 1917), and fig. 13, Plate V. "Coupled Vibrations" (Phil. Mag. July 1918). An extra bridle and pendulum were added, and three connectors substituted for the single one, each of the three connecting two of the pendulums. Later it was thought that two connectors were sufficient, and the apparatus was modified to obtain a result which might be more amenable to analytical treatment.

From the mathematical theory of three circuits coupled each to the other two, it was expected that the mechanical arangement would give for each pendulum three superposed

* Communicated by the Authors. 
vibrations. The periods of these vibrations were expected to be the same for each pendulun. The phases and amplitudes might, however, differ for each pendulum, thus giving very different resultant vibrations.

The results obtained with the first form of apparatus were even more complicated than was expected from three superposed vibrations, and on reflection this was seen to be due to the special arrangement in use. So it is proposed in this paper to describe this apparatus and give the figures obtained without dealing with its mechanical theory.

Results obtained with a modified apparatus will be dealt with later.

\section{Theory of.Three Mutually-interactixg Electric Circuits.}

The electric circuits are supposed to have self and mutual inductances, and capacities with resistances negligible.

Let $\mathrm{L}_{1}, \mathrm{~L}_{2} . \mathrm{I}_{3}$ be the self-inductances of the separate circuits, $\mathrm{S}_{1}, \mathrm{~S}_{2}, \mathrm{~S}_{3}$ their capacities, and $\mathrm{M}_{1}, \mathrm{M}_{2}, \mathrm{M}_{3}$ the mutual inductances between the second and third, the third and first, and the first and second circuits respectively. Then the simultaneous equations of motion may be written as follows:-

$$
\begin{aligned}
& \mathrm{L}_{1} \frac{d^{2} x}{d t^{2}}+\frac{v}{\mathrm{~S}_{1}}=\mathrm{M}_{3} \frac{d^{2} y}{d t^{2}}+\mathrm{M}_{2} \frac{d^{2} z}{d t^{2}}, \\
& \mathrm{I}_{2} \frac{d^{2} y}{d t^{2}}+\frac{y}{\mathrm{~S}_{2}}=\mathrm{M}_{1} \frac{d^{2} z}{d t^{2}}+\mathrm{M}_{3} \frac{d^{2} x}{d t^{2}}, \\
& \mathrm{I}_{4_{3}} \frac{d^{2} z}{d t^{2}}+\frac{z}{\mathrm{~S}_{3}}=\mathrm{M}_{2} \frac{d^{2} x}{d t^{2}}+\mathrm{M}_{1} \frac{d^{2} y}{d t^{2}},
\end{aligned}
$$

where $x, y$, and $z$ are the charges on the respective condensers.

The three couplings are given by



Suppose as solution that

$$
\left.\begin{array}{l}
x=\mathrm{A} e^{p i t}, \\
y=\mathrm{B} e^{p i t} \\
z=\mathrm{C} e^{p i t} .
\end{array}\right\} \cdot . . . . .
$$


Triple Pendulums with Mutual Lnteraction.

Substituting these in (1), (2), and (3), we obtain

$$
\begin{aligned}
& \left(\frac{1}{\mathrm{~S}_{1}}-\mathrm{L}_{1} p^{2}\right) v+p^{2} \mathrm{M}_{3} y+p^{2} \mathrm{M}_{2} z=0, \\
& \left.\begin{array}{l}
p^{2} \mathrm{M}_{3} x+\left(\frac{1}{S_{2}}-\mathrm{L}_{2} p^{2}\right) y+p^{2} \mathrm{M}_{1} z=0, \\
p^{2} \mathrm{M}_{2} x+p^{2} \mathrm{M}_{1} y+\left(\frac{1}{S_{3}}-\mathrm{I}_{3} p^{2}\right) z=0 .
\end{array}\right\} \cdot .
\end{aligned}
$$

Eliminating $x, y$, and $z$ from $(6)$ by the mesthod of determinants, we have

$$
\left|\begin{array}{rrr}
\left(\frac{1}{S_{1}}-\mathrm{L}_{1} p^{2}\right), & p^{2} \mathrm{M}_{3}, & \iota^{2} \mathrm{M}_{2}, \\
p^{2} \mathrm{M}_{3}, & \left(\frac{1}{\mathrm{~S}_{2}}-\mathrm{L}_{2} p^{2}\right), & p^{2} \mathrm{M}_{1}, \\
p^{2} \mathrm{M}_{2}, & p^{2} \mathrm{M}_{1}, & \left(\frac{1}{\mathrm{~S}_{3}}-\mathrm{L}_{3} p^{2}\right) .
\end{array}\right|=0
$$

This gives an equation of the sixth degree in $p$, viz.:-

$$
\begin{aligned}
& p^{6}\left[2 \mathrm{M}_{1} \mathrm{M}_{2} \mathrm{M}_{3}-\mathrm{L}_{1} \mathrm{~L}_{2} \mathrm{~L}_{3}+\mathrm{L}_{1} \mathrm{M}_{1}{ }^{2}+\mathrm{L}_{2} \mathrm{M}_{2}{ }^{2}+\mathrm{L}_{3} \mathrm{M}_{3}{ }^{2}\right] \\
& +p^{4}\left[\frac{\mathrm{L}_{2} \mathrm{~L}_{3}-\mathrm{M}_{1}{ }^{2}}{\mathrm{~S}_{1}}+\frac{\mathrm{I}_{3} \mathrm{~L}_{1}-\mathrm{M}_{2}{ }^{2}}{\mathrm{~S}_{2}}+\frac{\mathrm{L}_{1} \mathrm{~L}_{2}-\mathrm{M}_{3}{ }^{2}}{\mathrm{~S}_{3}}\right] \\
& -p^{2}\left[\frac{\mathrm{L}_{1}}{\mathrm{~S}_{2} \mathrm{~S}_{3}}+\frac{\mathrm{L}_{2}}{\mathrm{~S}_{3} \mathrm{~S}_{1}}+\frac{\mathrm{L}_{3}}{\mathrm{~S}_{1} \mathrm{~S}_{2}}\right]+\frac{\mathrm{I}}{\mathrm{S}_{1} \mathrm{~S}_{2} \mathrm{~S}_{3}}=0 . . .
\end{aligned}
$$

This is a cabic equation in $p^{2}$, of which the roots may be written, $p^{2}=p_{1}{ }^{2}, p_{2}{ }^{2}, p_{3}{ }^{2}$.

$$
\text { Then } \quad p= \pm p_{1}, \quad \pm p_{2}, \quad \pm p_{3} ;
$$

but the negative signs may be disregarded as they introduce nothing new.

Hence vibrations of three periods are set up.

Thus the general solution of the equations may be written $x=\mathrm{E}_{1} \sin \left(p_{1} t+\epsilon_{1}\right)+\mathrm{F}_{1} \sin \left(p_{2} t+\phi_{1}\right)+G_{1} \sin \left(p_{3} t+\chi_{1}\right)$, and similar equations for $y$ and $z$.

If the circuits were vibrating each isolated from the others, then their vibrations would be proportional to

$$
\begin{array}{r}
\left.\sin l t, \quad \begin{array}{r}
\text { in } m t, \text { and } \sin n t, \ldots . \\
l^{2}=\frac{1}{\mathrm{~L}_{1} \mathrm{~S}_{1}}, \\
m^{2}=\frac{1}{\mathrm{~L}_{2} \mathrm{~S}_{2}}, \\
n^{2}=\frac{1}{\mathrm{~L}_{3} \mathrm{~S}_{3}},
\end{array}\right\} . . . . . .
\end{array}
$$

where 
Then using equations (4) and (11), equation (8) may be written

$$
\begin{gathered}
p^{6}\left(1-\alpha^{2}-\beta^{2}-\gamma^{2}-2 \alpha \beta \gamma\right)-p^{4}\left[l^{2}\left(1-\alpha^{2}\right)+m^{2}\left(1-\beta^{2}\right)\right. \\
\left.+n^{2}\left(1-\gamma^{2}\right)\right]+p^{2}\left(l^{2} m^{2}+m^{2} n^{2}+n^{2} l^{2}\right)-l^{2} m^{2} n^{2}=0 . .
\end{gathered}
$$

Thus it is seen that in general the vibrations after coupling the circuits differ from the free vibrations of the separate systems.

The less the coupling the more nearly do the superposed vibrations approximate to those of the systems when free.

\section{Arrangement of Three Conneoted Pendulums.}

The apparatus shown in fig. 13, Plate V. "Coupled Vibrations" (Phil. Mag. July 1918) was adapted for the tripled pendulums. Figs. 1 and 2 give the side and end elevations

Fig. 1.-Side elevation.

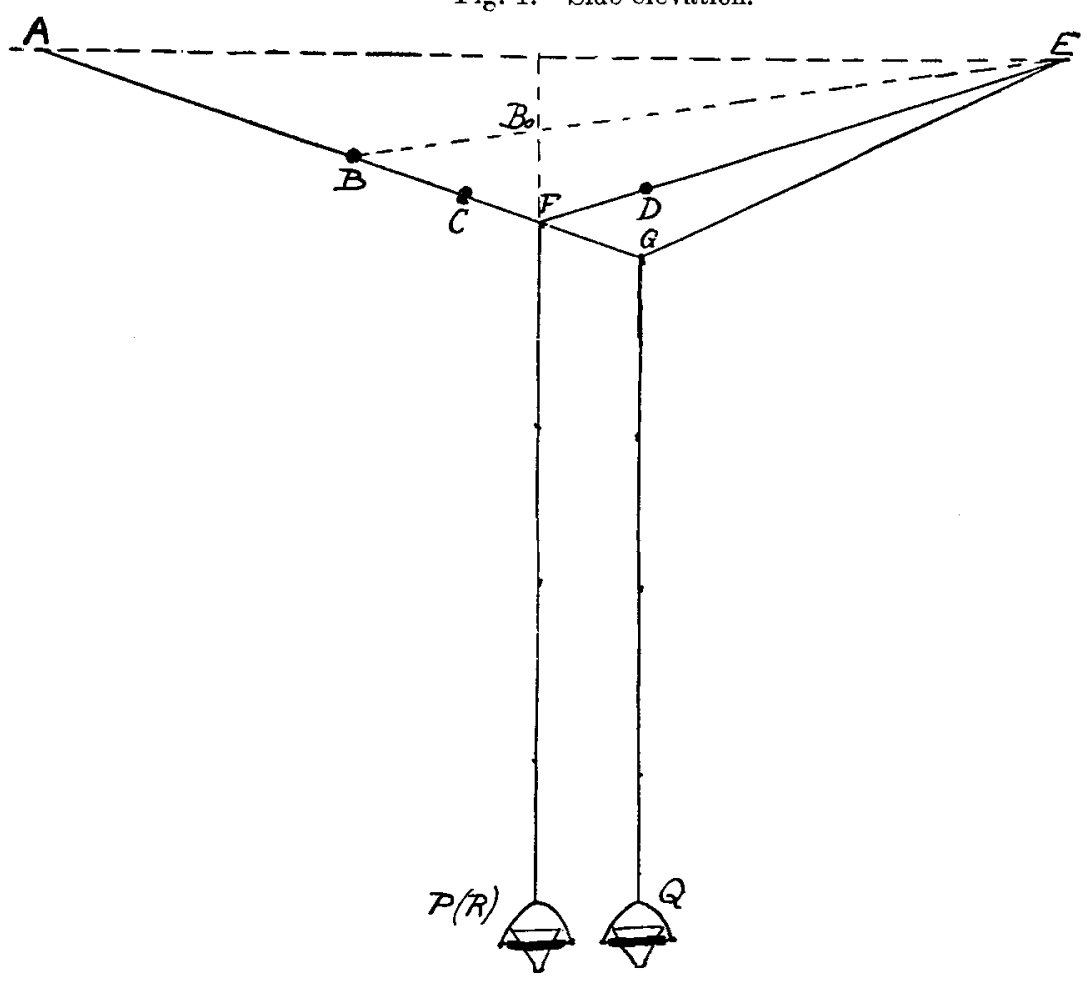

of the actual arrangement used. The masses are confined as far as possible to the bobs $P, Q$, and $R$, which are heavy carriers with funnels containing sand. 
In fig. 1 only two pendulums are visible, the third is hidden by FP. The positions of the bridles are determined by the three light connectors $\mathrm{BB}^{\prime}, \mathrm{CC}^{\prime}$, and $\mathrm{DD}^{\prime}$.

The normal oscillations occur in the plane of fig. 2 , and are recorded by sand traces on a black-board drawn perpendicular to the direction of vibration.

Fig. 2.-End elevation.



The trace from $Q$ is received on a narrow black-board. The pendulums are started when all the bobs are just above the boards, and afterwards the board containing the trace from $Q$ is moved until the three initial motions, shown by the traces, are in the same straight line.

If the advantages and disadvantages of this arrangement are considered, it is seen :-

(1) That although the three connectors make for generality, yet if $\mathrm{DD}^{\prime}$ is eliminated, the action of the pendulum-bob 
$P$ may still be transmitted through the connectors $B B^{\prime}$ and $\mathrm{CO}^{\prime}$ to the pendulum-bob $\mathrm{R}$. Further, the connector $\mathrm{DD}^{\prime}$ may tend to force in extra vibrations, so that four, or more vibrations may be felt by each bob.

(2) That the bridle droop being different for one pendulum may also complicate matters.

The bridle droops do not enter into these experiments in exactly the same way as in those of the Double-Cord Pendulums, "Coupled Vibrations" (Phil. Mag. Oct. 1917); for in that the bridle droop directly determined the length of the oscillating pendulums.

Suppose the pendulum $\mathrm{P}$ is considered, and the one connector at $\mathrm{BB}^{\prime}$. Then the two oscillations possible to this pendulum, if others are not forced upon it, are :-

(a) One about $\mathrm{AE}$;

(b) One about BE if $\mathrm{B}$ is held stationary. Now if the bridle $A F E$ is altered, but the connector $B$ is so adjusted that $\mathrm{BE}$ makes the same angle with the horizontal, then the period of the oscillation of the pendulum about this position is unaffected. For small oscillations, the effective length would be found by producing P'F upwards until it met the line joining $\mathrm{BE}$ in $\mathrm{B}_{0}$.

For this arrangement it is not easy to write down definite values for the couplings. However, from general considerations, it is seen that, if $\mathrm{BB}^{\prime}$ and $\mathrm{CC}^{\prime}$ are near $\mathrm{AA}^{\prime \prime}$, and $\mathrm{DD}^{\prime}$ to $\mathrm{EE}^{\prime \prime}$, the couplings will all be small. The coupling between two only will be large if those are connected near $F$, and the others near $\mathrm{A}$ or $\mathrm{E}$.

The early experiments were done with the apparatus as described. Later the connector ' $\mathrm{CC}^{\prime}$ was removed, and results obtained for certain couplings were found to be similar to those obtained when using three connectors.

\section{Photographic Records of Vibiations.}

Nine photographs of traces were taken with the three connectors in use (Pls. XI. \& XII.). Six others with only the two connectors $\mathrm{BB}^{\prime}$ and $\mathrm{CC}^{\prime}$, but otherwise the same arrangement (Pl. XIII.)

For details of the lengths mentioned in the table reference must be made to figures 1 and 2 . The masses of the bobs in these experiments were all the same and equal to $660 \mathrm{gms}$. In all the experiments the total depth of the bobs below $A \mathbf{E}$ was kept constant and equal to $140 \mathrm{cms}$. The distance between $\mathrm{AE}$ was $180 \mathrm{cms}$. The positions of $\mathrm{B}, \mathrm{C}, \mathrm{D}, \mathrm{F}$, and $\mathrm{G}$ will now determine the whole of the system. 
Table of Experimental Detiils.

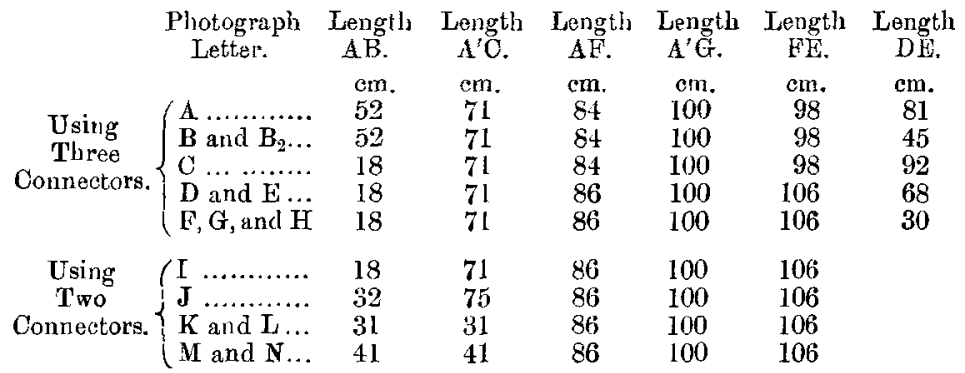

The table indicates that for photograph A (PI. XI.), the coupling due to the bridle droop is small, but, for this droop, that due to the connectors is large. The vibrations were produced by drawing aside the pendulum $\mathrm{P}$ at the point $\mathrm{F}$. The traces from the three bobs $P, Q$, and $R$ all show that there are more than two simple harmonic motions combining to produce the curves.

For the photographs $B$ and $B_{2}$ the coupling is still less between the pendulums $\mathrm{P}$ and $\mathrm{R}$. This is shown both in the table and in the traces. For photograph $B$ the pendulums were started by drawing $Q$ aside at $G$, and for $B_{2}$ by drawing $P$ aside at $F$. The trace of $P$ in photograph $B$ does not indicate more than two simple harmonic vibrations, nor are the traces in photograph $B_{2}$ very striking.

For photograph C, the coupling between the pendulums $\mathrm{P}$ and $R$ was considerably increased, but that between $P$ and $Q$ was lecreased. The resultant effect was to materially increase all the couplings as $\mathrm{P}$ acted on $\mathrm{Q}$ by means of the connectors $\mathrm{DD}^{\prime}$ and $\mathrm{CC}^{\prime}$, which were both tightly coupled. All these traces can be seen to contain more than two simple harmonic motions.

For the photographs D to $\mathrm{H}$ inclusive the droop of the bridle was increased. For traces shown on photographs $\mathrm{D}$ and $\mathrm{E}$, the couplings between all the pendulums due to the position of the connectors were decreased, but this was compensated by the increased droop. With $\mathrm{P}$ pulled aside (see D), the traces from $P$ and $Q$ only appear to be the resultant of two simple harmonic vibrations, but the beats in $R$ are slower on reaching their maximum than in falling to their minimum. All the traces with $Q$ pushed aside (see E) show more complicated curves. These could be obtained by compounding three simple harmonic vibrations of the proper phase and amplitude.

Phil. Mag. S. 6. Vol. 40, No. 239. Nov. 1920, 2 S 
For F, G, and $\mathrm{H}$ (Pl. XII.), the coupling between pendulums $P$ and $R$ was decreased by moving the connector $D^{\prime}$ nearer to $\mathrm{E}$. 'The curves are very similar, $\mathrm{F}$ was obtained with $Q$ pushed aside, and $G$ with $R$ pushed aside. From the photograplus it is seen that the couplings are small between $P$ and each of the other pendulums, but that between $Q$ and $R$ is very much larger. The interaction between the pendulums $Q$ and $R$ does not seem to be communicated to $P$ at all, although the reaction of the slow waxing and waning of the amplitude of $P$ is clearly seen in the traces of both the other pendulums.

Photograph $\mathrm{H}$ was obtained with an arrangement of pendulums like those used for $F$ and $G$. $R$ was started and after three complete cycles of change was held stationary; the pendulum then settled quickly to a state showing two superposed simple harmonic vibrations, as in coupled pendulums.

At this point it was thought probable that the two connectors $B$ and $C$ would be sufficient. $D$ was removed. Everything else was kept the same. The photograph I (PI. XIII.) shows traces with the couplings between $\mathrm{P}$ and each of the other pendulums considerably reduced, but other things much the same.

The connectors were then lowered considerably, and curve J was obtained by drawing aside $R$. This was found to be almost identical with $G$, which shows that connector $D$ was superfluons.

Photographs $\mathrm{K}$ and $\mathrm{T}$ were obtained with the two connectors at the same position on the cords. The photographs show which bohs were drawn aside, and the resultant effect was that of a light hob driving one heavy bob which is composed of the other two. There is little to indicate more than two harmonic vibrations in the curves.

$\mathrm{M}$ and $\mathrm{N}$ were obtained with the connectors together on the cords, but with the coupling increased. Studying the four last photographs carefully, it is seen that the two pendulums which are the driven ones to begin with do not give exactly identical curves, the distance between the nodes is gradually increasing. This points to the fact that there are more than two simple harmonic vibrations involved.

Other experiments have already been carried out with a simpler arrangement of three interconnected pendulums, but. these are reserved for a separate paper.

Nottiugham, July 14, 1920. 


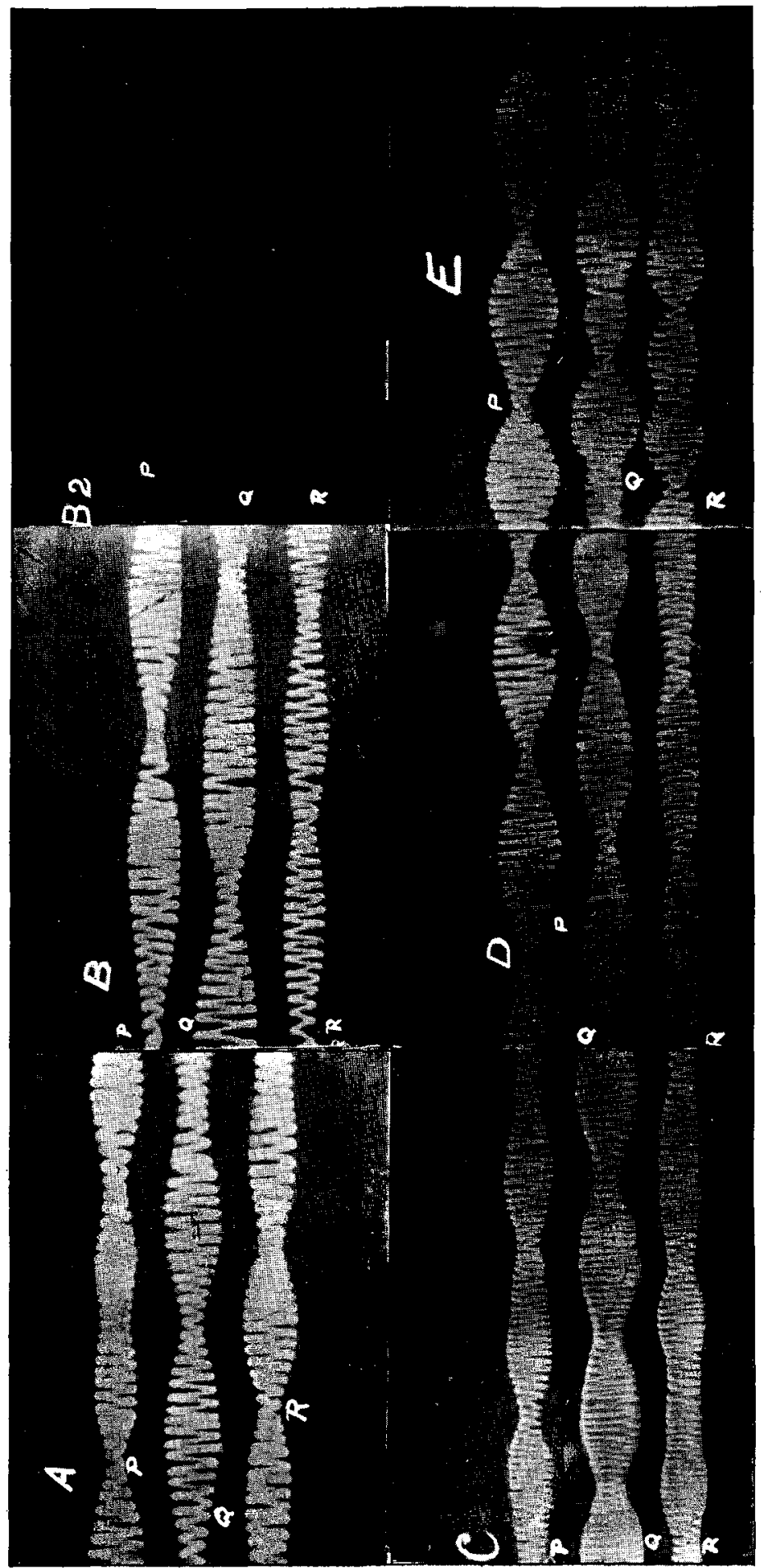


Barton \& Browntra. $\quad$ Phil. Mag. Ser. 6, Vol, 40. Pl. XII.

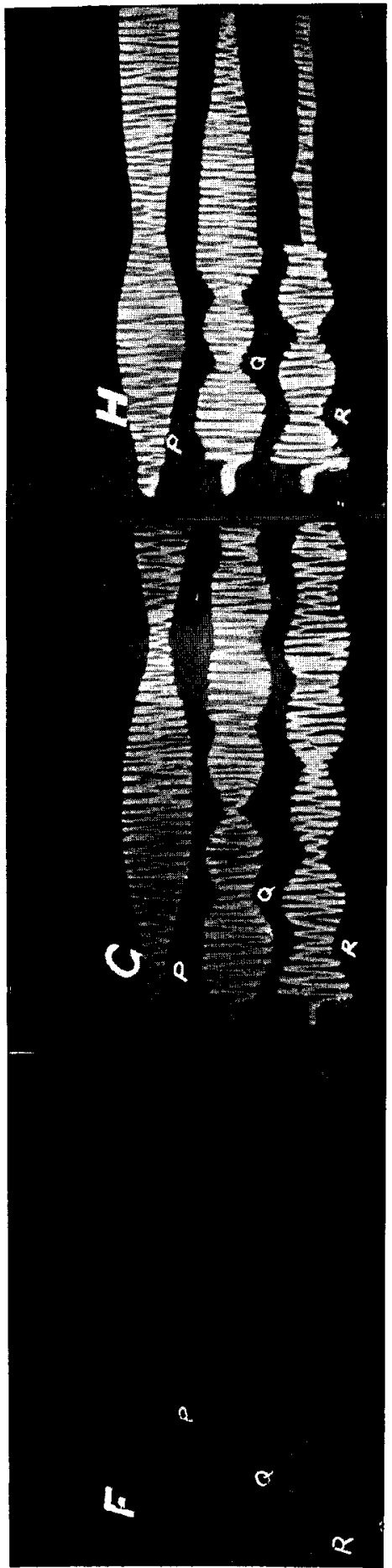




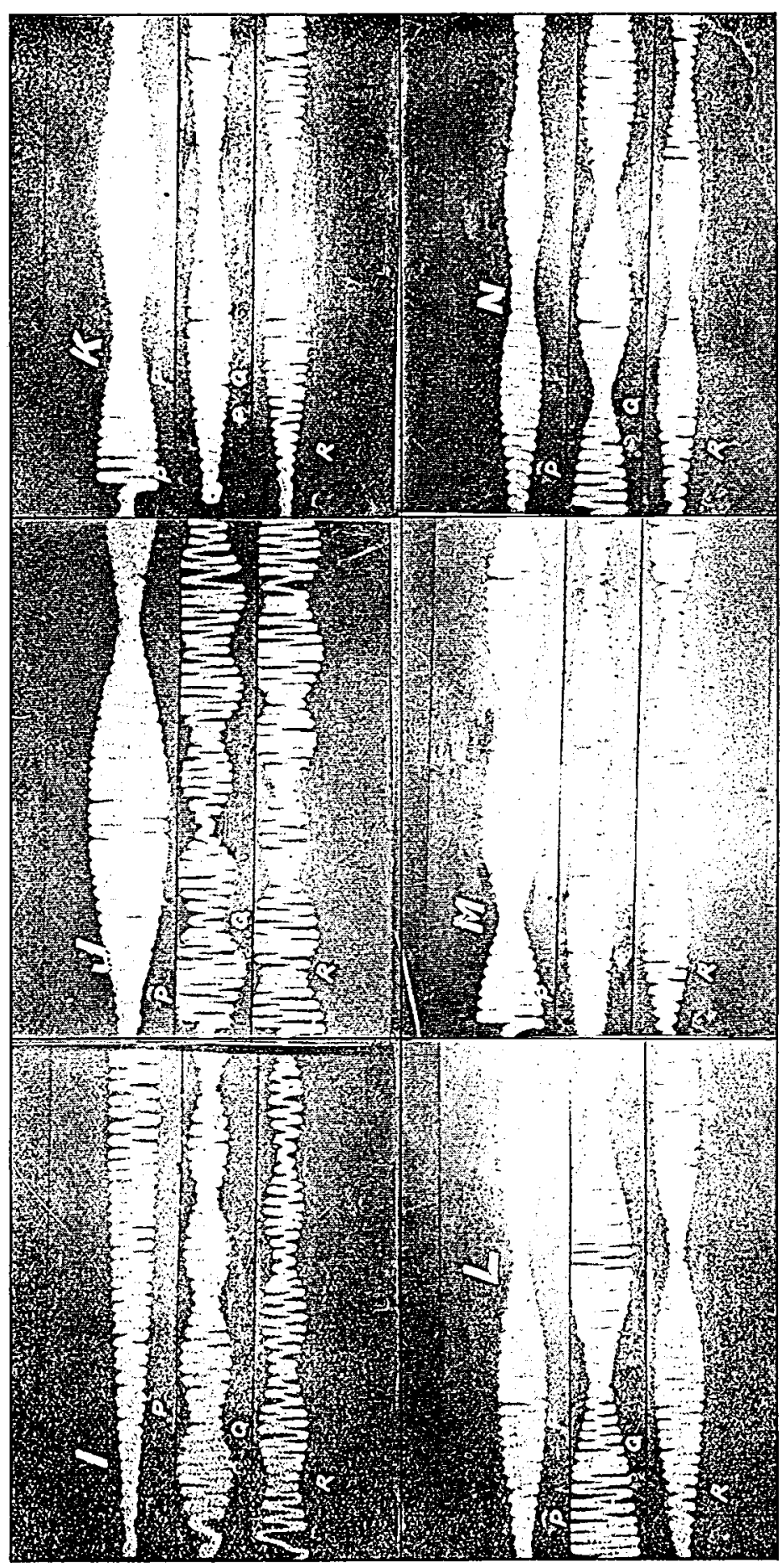

